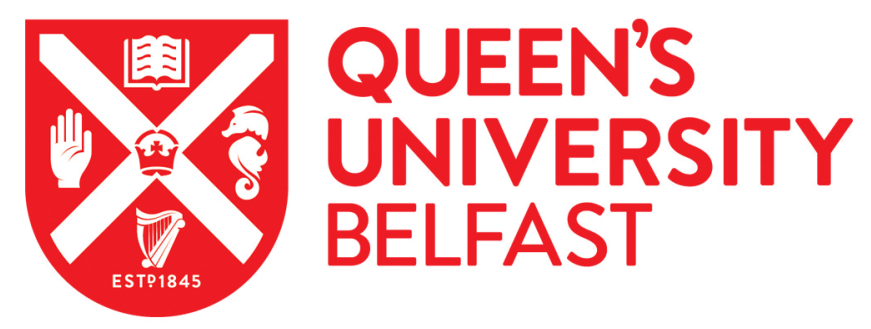

\title{
Quantification of Hydroxyl Radicals in Photocatalysis and Acoustic Cavitation: Utility of Coumarin as a Chemical Probe
}

\author{
De-Nasri, S., Nagarajan, S., Robertson, P., \& Ranade, V. (2020). Quantification of Hydroxyl Radicals in \\ Photocatalysis and Acoustic Cavitation: Utility of Coumarin as a Chemical Probe. Chemical Engineering Journal. \\ https://doi.org/10.1016/j.cej.2020.127560
}

Published in:

Chemical Engineering Journal

Document Version:

Peer reviewed version

Queen's University Belfast - Research Portal:

Link to publication record in Queen's University Belfast Research Portal

\section{Publisher rights}

Copyright 2020 Elsevier.

This manuscript is distributed under a Creative Commons Attribution-NonCommercial-NoDerivs License

(https://creativecommons.org/licenses/by-nc-nd/4.0/), which permits distribution and reproduction for non-commercial purposes, provided the author and source are cited.

\section{General rights}

Copyright for the publications made accessible via the Queen's University Belfast Research Portal is retained by the author(s) and / or other copyright owners and it is a condition of accessing these publications that users recognise and abide by the legal requirements associated with these rights.

Take down policy

The Research Portal is Queen's institutional repository that provides access to Queen's research output. Every effort has been made to ensure that content in the Research Portal does not infringe any person's rights, or applicable UK laws. If you discover content in the Research Portal that you believe breaches copyright or violates any law, please contact openaccess@qub.ac.uk. 


\title{
Quantification of Hydroxyl Radicals in Photocatalysis and Acoustic Cavitation: Utility of Coumarin as a Chemical Probe
}

\author{
Sebastien J De-Nasri, Sanjay Nagarajan, Peter K J Robertson and Vivek V Ranade* \\ School of Chemistry and Chemical Engineering, David Keir Building, Queen's University \\ Belfast, Belfast, UK, BT9 5AG \\ ${ }^{*}$ Corresponding Author: Professor Vivek Ranade (․ranade@qub.ac.uk)
}

\begin{abstract}
In-situ hydroxyl radical production is a characteristic of advanced oxidation processes (AOPs) and its quantification is crucial for assessing the performance of these processes. Direct $\mathrm{OH}$ quantification is however unlikely due to their high reactivity and short life-time $\left(\sim 10^{-6} \mathrm{~s}\right)$. Therefore, chemical probes (like coumarin) are often used to indirectly quantify $\mathrm{OH}$ radicals. The resulting hydroxylated products of these probe molecules are relatively stable and detectable (like 7-hydroxycoumarin; 7OHC); their concentration is usually related to the $\mathrm{OH}$ radical concentration. Reported literature suggests the use of a constant fraction (6.1\%) as the yield of $7 \mathrm{OHC}$ from total $\mathrm{OH}$ radicals generated $(\delta)$. This was originally determined from $\psi$-irradiation studies of coumarin and translated across to other AOPs. It is however highly unlikely that this fraction is same across other AOPs. To address this gap and as a means of comparing AOPs, in the present work, we used coumarin as a probe to quantify $7 \mathrm{OHC}$ during acoustic cavitation (AC) and photocatalysis (PC) and determined the $\mathrm{OH}$ radical yields. Since $\delta$ cannot be determined directly, an alternative and simple means of comparison based on the amount of $\mathrm{OH}$ radicals utilised for desired reactions i.e., hydroxylation was exploited. Based on the proposed means of comparison, it was determined that $\mathrm{OH}$ radicals utilised by the probe was higher for $\mathrm{PC}$ than $\mathrm{AC}$ by $\sim 25$ times under the considered process operating conditions. The presented results will be useful for researchers and engineers interested in quantifying hydroxyl radicals and optimising AOPs.
\end{abstract}

Key words: Hydroxyl radicals, coumarin, cavitation, photocatalysis, quantification 


\section{Introduction}

The role of advanced oxidation processes (AOPs) in the wastewater treatment industry has been examined extensively in recent years [1-3]. This is attributed to their ability to remove pollutants resistant to conventional treatment [4]. A defining characteristic of AOPs is their in-situ generation of oxidising radicals such as hydroxyl $(\mathrm{OH})$ radicals. Although numerous radical species are reported, $\mathrm{OH}$ radicals are frequently assigned as the major species responsible for the oxidation of compounds due to their strong oxidation potential of $2.8 \mathrm{~V}[1,5]$. Cavitation and photocatalysis are two attractive AOPs which have gained attention in wastewater treatment applications due to their applicability to a range of pollutants and synergistic operations[6-12]. Acoustic cavitation (AC) is the formation and subsequent collapse of vapour filled cavities using ultrasonic waves which generate localised hotspots that lead to the formation of $\mathrm{OH}$ radicals. On the other hand, during photocatalysis (PC), when a semiconductor photocatalyst is illuminated with light of sufficient energy, electron excitation from valence band to conduction band occurs. The holes left behind in the valence band then interacts with adsorbed water to form $\mathrm{OH}$ radicals. Although $\mathrm{OH}$ radicals are produced in-situ in both of these AOPs, the nature of pollutant and its interaction with the bubble or photocatalyst surface is crucial for their oxidation by $\mathrm{OH}$ radicals. This means that the $\mathrm{OH}$ radical utilisation for desired reactions is process specific. Nonetheless, the primary indicator of the process efficiency for comparing AOPs has often been the total $\mathrm{OH}$ concentrations. The characteristic high reactivity of $\mathrm{OH}$ radicals and a short lifespan $\left(\sim 10^{-6} \mathrm{~s}\right)$ [13] makes it difficult to quantify them directly and also renders that the quantification of total $\mathrm{OH}$ radicals generated in-situ becomes highly unlikely.

To overcome the issue of direct quantification, a range of indirect methods have been developed, including; emission spectroscopy, laser induced fluorescence, electron spin resonance, spin trap and chemical probes [14-19]. Amongst the reported methods, chemical probes are a useful means of quantifying $\mathrm{OH}$ radicals due to their low-cost and relatively short analysis time. Several probes are frequently reported for $\mathrm{OH}$ quantification, namely; salicylic acid, terephthalic acid and coumarin. For instance, salicylic acid has been examined as a probe for the quantification of $\mathrm{OH}$ from PC [20], Fentonbased reactions [21] and cavitation [22,23]. Here the total $\mathrm{OH}$ radical concentration is determined as the sum of quantified hydroxylation products (2,3 dihydroxybenzoic acid, 2,5 dihydroxybenzoic acid and catechol) formed during the process. Similarly, Hirano \& Kobayashi utilised coumarin to quantitatively detect $\mathrm{OH}$ radicals during $\mathrm{AC}$, where the concentration of 7-hydroxycoumarin (7OHC) was directly related to the concentration of $\mathrm{OH}$ radicals [24]. 
Hydroxylated products formed as a result of the reaction between $\mathrm{OH}$ radicals and the probe molecules are monitored and related to the concentration of $\mathrm{OH}$ radicals based on stoichiometry. Furthermore, to calculate the total $\mathrm{OH}$ radicals, several approximations have been made. For instance, Zhang et al [25] estimated that $6.1 \%$ of all $\mathrm{OH}$ radicals are scavenged as the fluorescent hydroxylation product $(7 \mathrm{OHC})$ when coumarin was used as the probe molecule. This approximation was attained from $7 \mathrm{OHC}$ yields obtained from $\gamma$-irradiation studies of coumarin and therefore may not be valid when translated to other AOPs. It is apparent that when using indirect methods of $\mathrm{OH}$ quantification such as probe based methods, the hydroxylated product yields are process specific. However, ignoring process conditions, hydroxylated product yields between methods have been translated to report total $\mathrm{OH}$ concentration. This renders the relation between hydroxylated product and total $\mathrm{OH}$ radicals as being inconsistent. In another example, when terephthalic acid was used as a probe to determine the total $\mathrm{OH}$ concentration produced during $\mathrm{PC}$, an $\mathrm{OH}$ radical yield from laser photolysis of $\mathrm{H}_{2} \mathrm{O}_{2}$ was used to relate the concentration of hydroxylation product 2-hydroxyterephthalic acid to total $\mathrm{OH}$ radicals produced [26]. With the analytical quantification of total $\mathrm{OH}$ radicals being unlikely, this is the commonly utilised approach to determine total $\mathrm{OH}$ radicals and is rather misleading $[25,27,28]$. It is therefore important to establish process specific $\mathrm{OH}$ yields instead of reporting total $\mathrm{OH}$ radical concentrations as a means of comparing AOPs.

The aim of this study was to address this gap by employing coumarin as the probe molecule to quantify $\mathrm{OH}$ radicals produced by two different AOPs; $\mathrm{AC}$ and $\mathrm{PC}$ and compare their performances. Coumarin was selected as a probe due to its solubility in water, weakly luminescent state compared to its hydroxylated product $(7 \mathrm{OHC})$ and ease of quantification. The $\mathrm{OH}$ quantification procedure was established by initially proposing a pathway for the fate of $\mathrm{OH}$ radicals which was used to make deliberations, identify key yields and define relevant concentrations. The proposed procedure was then also used to assess previously reported coumarin based systems and address assumptions made therein to develop a method which can report a more meaningful process specific $\mathrm{OH}$ radical concentration.

\section{Methodology}

\subsection{Materials}

Coumarin and 4-Hydroxycoumarin were obtained from Acros organics, 3-Hydroxycoumarin, 3-(2Hydroxyphenyl)propionic acid, and 7-hydroxycoumarin (7OHC) were obtained from Sigma-Aldrich, 
trans-o-Coumaric acid was obtained from Tokyo chemical Industry Co., and 6-Hydroxycoumarin was obtained from Fisher scientific. All chemicals had purities of $98 \%$ or higher. Photocatalyst $\mathrm{P}_{25} \mathrm{TiO}_{2}$ was purchased from Evonik. Methanol $(\geq 99.8 \%)$ and acetic acid $(\geq 99.8 \%)$ were procured from Fisher Scientific and Sigma Aldrich, respectively. All chemicals were used as received. Stock solutions of coumarin $(8.2 \mathrm{mM})$ and hydroxycoumarins $(20 \mu \mathrm{M})$ were prepared to their desired concentration and diluted to operating concentrations with distilled water when required. A range of diluted solutions were prepared, and calibration curves of the standards were obtained using high performance liquid chromatography (HPLC). HPLC mobile phases were prepared using deionised water.

\subsection{Experimental procedures}

All experiments were carried out in $250 \mathrm{~mL}$ screw cap bottles, with $200 \mathrm{~mL}$ working volume of $100 \mu \mathrm{M}$ coumarin solution. $1.5 \mathrm{~mL}$ samples were taken at dedicated time intervals using a needle and syringe for analysis. Samples were then filtered with Millex syringe filters (pore diameter $-0.22 \mu \mathrm{m}$ ) into HPLC vials for analysis. Treatment time for each process was 120 minutes. AC experiments were performed using a 500 W VCX 500 ultrasound probe $(20 \mathrm{kHz})$ positioned inside the screw cap bottles with a tip depth of $1 \mathrm{~cm}$ (Figure $1 \mathrm{a}$ ). The tip of the ultrasound probe had a diameter of $13 \mathrm{~mm}$ and was operated at $90 \%$ amplitude. A separate $200 \mathrm{~mL}$ volume was prepared for each time point to avoid changes to tip dip height upon sampling. Experiments were performed in a cold water bath and sonicated in 20minute intervals to maintain a solution temperature below $40^{\circ} \mathrm{C}$. PC experiments were performed with $\mathrm{P} 25 \mathrm{TiO}_{2}$ photocatalyst loading of $0.1 \mathrm{~g} / \mathrm{L}$. A magnetic stirrer bar was placed inside each bottle which was positioned on a magnetic stirrer (operated at $\sim 1000 \mathrm{rpm}$ ) and placed $4 \mathrm{~cm}$ in front of a UVA/36 W Philips lamp (Figure $1 \mathrm{~b}$ and c). Prior to illumination, solutions were stirred in the dark for 40 minutes to ensure adsorption equilibrium between the photocatalyst and coumarin (minimum adsorption time determined according to 24-hour adsorption experiment, supplementary information Figure S1). PC experiments were initiated by switching on the lamp following dark adsorption period. A light control study was performed at the same conditions aforementioned, but in absence of $\mathrm{TiO}_{2}$, to determine coumarin loss by UV light (photolysis). 
a)

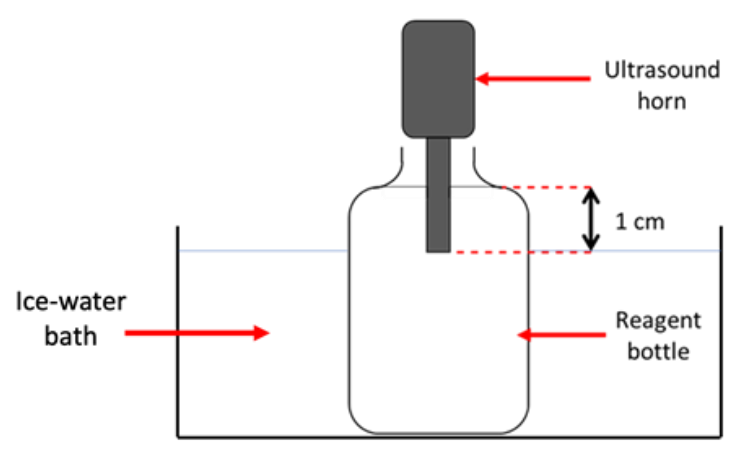

b)

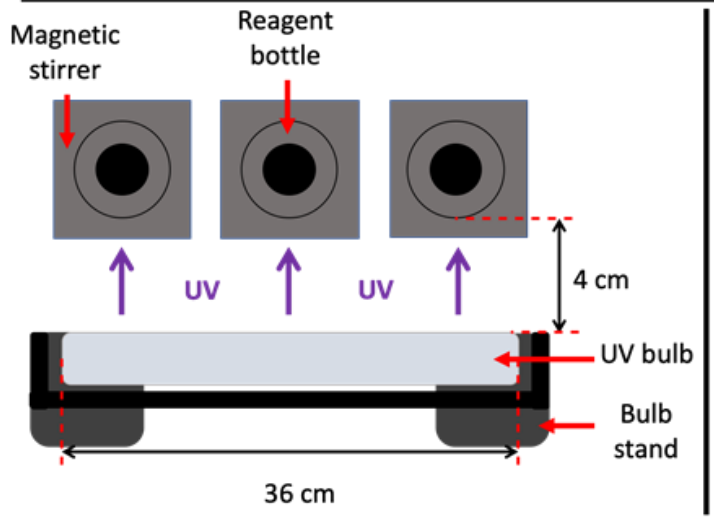

c)

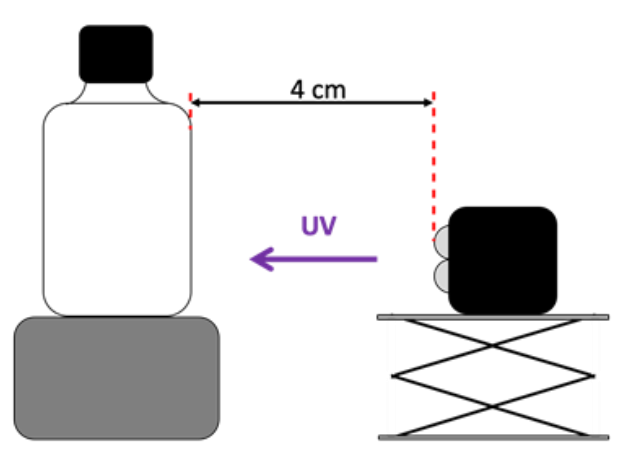

Figure 1 - Schematic of experimental setups used for acoustic cavitation (a) and photocatalysis (b, top view and c, side view)

Sample analysis was performed using a HPLC. A Kinetex Phenyl Hexyl column was used for this purpose. A mobile phase flow rate of $1 \mathrm{~mL} / \mathrm{min}$ was used. A solvent gradient between two mobile phase solutions; solvent A and B (solvent A: $89 \%$ de-ionised water, $10 \%$ methanol and $1 \%$ Acetic acid, Solvent B: $89 \%$ methanol, $10 \%$ de-ionised water and $1 \%$ Acetic acid) was used to mobilise the samples through the stationary phase. A linear flow gradient from $90 \% \mathrm{~A}, 10 \% \mathrm{~B}$ (run-time $=0 \mathrm{~min}$ ) to $40 \% \mathrm{~A}, 60 \% \mathrm{~B}$ (run-time $=10 \mathrm{~min}$ ) gave the most effective separation between components. An additional 3 minutes run-time was added to flush the column in between runs. $5 \mu \mathrm{L}$ sample volume was injected into the column using an autosampler. The samples were analysed using an Agilent 1100 HPLC G1321A Fluorescence Detector (excitation wavelength: $332 \mathrm{~nm}$, emission wavelength $450 \mathrm{~nm}$ ) for 7OHC, and an Agilent 1100 HPLC G1365B Multi-Wavelength Detector (signal wavelength: $277 \mathrm{~nm}$ ) for coumarin and all other compounds. Calibration curves were prepared for each compound to determine their relative concentrations during experiments. 


\section{3. $\mathrm{OH}$ radical generation and utilisation}

The fate of $\mathrm{OH}$ radicals produced from $\mathrm{AC}$ and $\mathrm{PC}$ are given in Figure $2 . \mathrm{OH}$ radicals are formed at the surface of the catalyst (PC, Figure 2a) or the inner cavity (AC, Figure 2b) (as mentioned in section 1) and, in both cases, can diffuse to other regions $[29,30]$. These pathways are taken as the primary sources of $\mathrm{OH}$ radicals for each process and their complete quantification represents the total $\mathrm{OH}$ radical concentration $\left([\mathrm{OH}]_{T}\right)$. Quantification of $[\mathrm{OH}]_{T}$ is highly unlikely and for probe based quantification, it depends on the nature of the probe molecule and process conditions. Instead of trying to determine $[\mathrm{OH}]_{\mathrm{T}}$, various specific concentrations and yields can be defined and determined as a means of comparing AOPs. The three yields leading to $[\mathrm{OH}]_{\mathrm{T}}$ are $\alpha, \beta$ and $\delta$. The significance of these yields as well as the feasibility to calculate them are discussed in this section.

Figure 2 indicates that a particular fraction of generated $\mathrm{OH}$ radicals $\left(\alpha[\mathrm{OH}]_{\mathrm{T}}\right)$ react with the probe and the remaining fraction $\left((1-\alpha)[\mathrm{OH}]_{\mathrm{T}}\right)$ will undergo alternative reactions (e.g. recombination) not involving the probe. $\alpha[\mathrm{OH}]_{\mathrm{T}}$ corresponds to the fraction of $\mathrm{OH}$ radicals utilised by the probe and can be represented as $[\mathrm{OH}]_{1}$. The yield $\alpha$ can thus be defined by Equation (1). This yield represents the ratio of utilised $\mathrm{OH}$ radicals for hydroxylation to total produced $\mathrm{OH}$ radicals. However, the requirement of $[\mathrm{OH}]_{\mathrm{T}}$ to calculate this yield limits its use. Additionally, $\alpha$ is also dependent on the physico-chemical properties of the probe and its mode of interaction with the $\mathrm{OH}$ radicals.

$\alpha=\frac{[\mathrm{OH}]_{1}}{[\mathrm{OH}]_{\mathrm{T}}}$

As the system in consideration is based on coumarin dosimetry, [D] can be used to represent the mono-hydroxylated product 7OHC. Any hydroxycoumarin product can be chosen as [D], however, since $7 \mathrm{OHC}$ can be distinctly identified fluorometrically and unambiguously, it was chosen as the main hydroxylated product. This allows for $\beta$ to be defined according to Equation (2). This yield represents the fraction of $[D]$ formed from utilised $\mathrm{OH}$ radicals.

$$
\beta=\frac{[D]}{[O H]_{1}}
$$




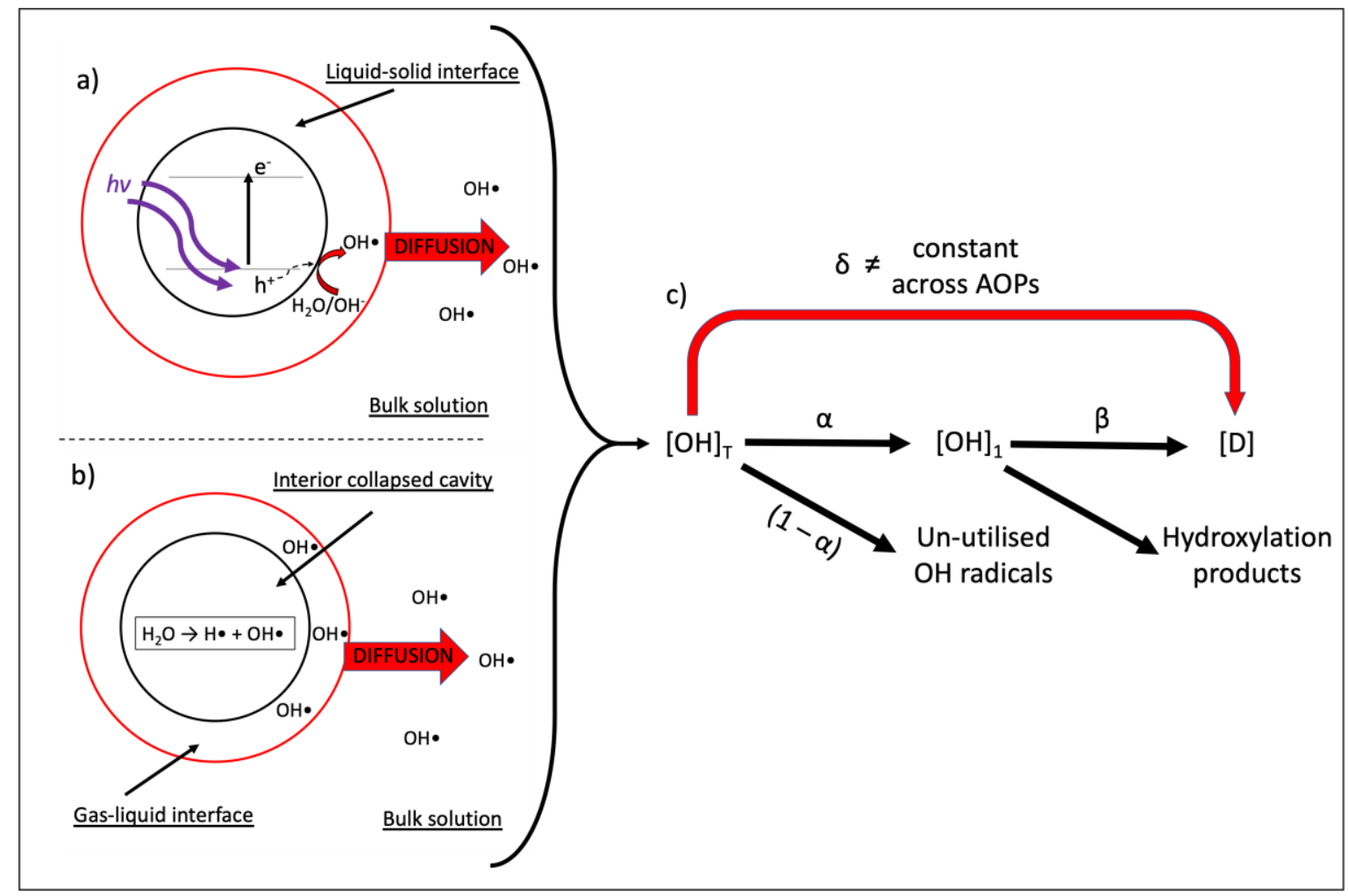

Figure 1 - Schematic describing $\mathrm{OH}$ radical formation during a) photocatalysis and $\mathrm{b}$ ) cavitation, and c) a suggested pathway and yields for $\mathrm{OH}$ radicals during reaction with a chemical probe. $[\mathrm{OH}]_{T}-$ total $\mathrm{OH}$ radical concentration, $[\mathrm{OH}]_{1}$ - concentration of utilised $\mathrm{OH}$ radicals, $[D]$ - concentration of detectable product, $\alpha$ - fraction of $[\mathrm{OH}]_{T}$ reacting with probe molecule, $\beta$ - fraction of $[\mathrm{OH}]_{1}$ used towards detectable product [D], and $\delta$ - fraction of $[\mathrm{OH}]_{\mathrm{T}}$ used towards detectable product [D]

The final yield, $\delta$, represents the overall yield of $[D]$ produced from $[O H]_{T}$ generated. This is a convenient means to relate the concentration of a detectable product directly to that of total produced $\mathrm{OH}$ radicals in a process. Again, the need for a known $[\mathrm{OH}]_{\mathrm{T}}$, limits the use of this yield.

$\delta=\frac{[D]}{[O H]_{T}}=\alpha \beta$

As mentioned in section 1 , chemical probes have been previously used to quantify total $\mathrm{OH}$ radicals on the following basis,

(i) relating the concentration of [D] to $\mathrm{OH}$ radical concentration stoichiometrically and

(ii) applying a $\delta$ yield to calculate $[\mathrm{OH}]_{\mathrm{T}}$

The stoichiometric determination of $\mathrm{OH}$ radicals required to produce $[D]$ is valid, however there are inconsistencies surrounding $\delta$ due the ambiguous use of $[\mathrm{OH}]_{\mathrm{T}}$. Specifically, for coumarin based $\mathrm{OH}$ quantification methods, $\delta$ yield determined from $\gamma$-irradiation of coumarin have been used to calculate $[\mathrm{OH}]_{\mathrm{T}}$ for various AOPs. This method assumes $\delta$ is constant across AOPs and $\gamma$-irradiation. 
Although this is unlikely, it is frequently reported $[25,27,28]$. Our group had also reported results based on these assumptions, however, revisiting the $\mathrm{OH}$ radical quantification pathway enabled us to devise the proposed methodology.

Zhang et al [25] utilised radiation chemical yields (no. of molecules/100eV) from two $\gamma$-irradiation studies to determine $\delta$ yield for $\gamma$-irradiation Equation (4) and applied this to their PC study. This resulted in an approximation that $6.1 \%$ of all $\mathrm{OH}$ radicals are scavenged as $7 \mathrm{OHC}$ in coumarin solutions. Although this may be true for $\gamma$-irradiation it may not be the case for other AOPs.

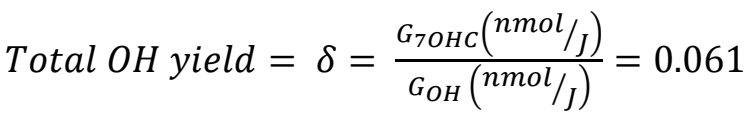

Applying the same $\delta$ yield across AOPs assumes it to be constant regardless of the system and process conditions involved. However, when the proposed $\mathrm{OH}$ system is considered it can be seen that for $\delta$ to be constant across processes, both $\alpha$ and $\beta$ must also be constant. Although it may be feasible for $\beta$ to remain constant, given that it represents the yield of a common reaction across all processes, it is unlikely $\alpha$ will also be constant across different AOPs. $\alpha$ depends on the contact pattern between $\mathrm{OH}$ and the probe molecule, which tends to vary across AOPs according to their methods of $\mathrm{OH}$ generation and even within AOPs due to difference in process conditions. For example, $\mathrm{P} 25 \mathrm{TiO}_{2}$, a UV activated photocatalyst, forms $\mathrm{OH}$ radicals from water and due to its higher coumarin adsorption capability might produce more $7 \mathrm{OHC}$ when compared to $\mathrm{WO}_{3}$, a visible light activated photocatalyst with limited coumarin adsorption and whose $\mathrm{OH}$ radical generation is predominantly via the superoxide radical route [28]. For the two AOPs considered in this work (PC and AC) it has been demonstrated that each of their regions (Figure 2) attribute to the overall decomposition of a probe molecule to varying degrees [29-31] according to its physico-chemical properties. The very different nature in location of $\mathrm{OH}$ radical generation and their contact with the probe molecule in different AOPs, make it highly unlikely that the extent of utilisation $(\alpha)$ remains constant across AOPs despite using the same probe molecule. Therefore, utilising $\delta$-yields from other processes does not provide authentic total concentrations of $\mathrm{OH}$ radicals as presented in literature thus far.

$\delta$-yield may become a viable means for reporting $[\mathrm{OH}]_{T}$, when $[\mathrm{OH}]_{1}$ tends to $[\mathrm{OH}]_{\mathrm{T}}$. This has been achieved with $\gamma$-irradiation studies of sodium formate. The technique for quantification of radical species in $\gamma$-irradiation has been established as; selecting appropriate solvent, measuring chemical change, and assume reaction sequence to relate chemical change to the desired radical species [32]. 
For the sodium formate and oxygen (Equations 5 and 6) system, the chemical radiation yield of $\mathrm{OH}$ $\left(\mathrm{G}_{\mathrm{OH}}\right)$ was determined by relating the concentration of $\mathrm{CO}_{2}$ with the concentration of $\mathrm{OH}$.

$$
\begin{aligned}
& \mathrm{HCOO}^{-}+\mathrm{OH} \rightarrow \mathrm{OH}^{-}+\mathrm{HCOO}\left(\text { or } \mathrm{H}_{2} \mathrm{O}+\mathrm{COO}^{-}\right) \\
& \mathrm{O}_{2}+\mathrm{HCOO}\left(\text { or } \mathrm{COO}^{-}\right) \rightarrow \mathrm{HO}_{2}\left(\text { or } \mathrm{O}_{2}^{-}\right)+\mathrm{CO}_{2}
\end{aligned}
$$

This procedure equates $[\mathrm{OH}]_{1}$ to $[\mathrm{OH}]_{T}$ by monitoring the detectable product $[D]$. This was achieved by selecting appropriate operating conditions (e.g. sufficient $\mathrm{O}_{2}$ concentrations) to minimise undesirable side reactions, ensuring the concentration of scavenger ( $\left.\mathrm{HCOO}^{-}\right)$was sufficiently high to scavenge $\mathrm{OH}$ radicals, and accounting for (spur) scavenging using the appropriate correction factors [32,33]. Applying these measures essentially equates $\alpha$ to 1 in Equation (1) and allows for the assumption that $[\mathrm{OH}]_{T}=[\mathrm{OH}]_{1}$. This is further validated by numerous $\gamma$-irradiation studies[33-36] reporting radiation chemical yields with a good agreement of $\mathrm{OH}$ radiation yield at neutral $\mathrm{pH}$ as 2.7 $( \pm 0.07)$ molecules $/ 100 \mathrm{eV}$. Therefore, it is feasible to calculate $[\mathrm{OH}]_{\mathrm{T}}$ to determine $\delta$ for $\psi$-irradiation processes.

No studies have however been performed into the total radical yields of $A C$ and PC processes making it impossible to determine the total amount of $\mathrm{OH}$ radicals in a similar manner. Furthermore, both processes represent non-homogeneous systems (Figure 2) which presents additional difficulties for quantification studies. The dependency of $\alpha$ on the physico-chemical properties of the probe as well as location of radical generation and nature of their contact with the probe molecules is a significant restriction when investigating radical yields. For example, Leandri et al [37] investigated the application of coumarin as a quantitative probe during PC and found its low solubility restricts complete surface saturation of the catalyst, making quantification of total $\mathrm{OH}$ radicals impossible. Additionally, Zupanc et al [23] attempted to quantify $\mathrm{OH}$ radicals during hydrodynamic cavitation and demonstrated higher concentrations of the probe molecule (salicylic acid) influences the fluid properties, which affects the degree of cavitation (and $\mathrm{OH}$ radical mediated reactions). These difficulties present a degree of uncertainty when reporting $[\mathrm{OH}]_{\mathrm{T}}$ with such probes.

The difficulty in determining $[\mathrm{OH}]_{T}$ may shift the focus from utilising $\delta$ to $\beta$. As both $[\mathrm{D}]$ and $[\mathrm{OH}]_{1}$ are relatively simple to determine in a process and $\beta$ is a convenient means of determining probe reacted ([P]). However, it is highly likely that $\beta$ may remain constant across AOPs and also be dependent on [D] which is subject to degradation [38,39]. Additionally, the degree of degradation of [D] will be dependent on the operating conditions and nature of the process which may result in a lack of 
constancy when translating across AOPs. To avoid the same uncertainties as experienced with $\delta$, simply reporting $[\mathrm{OH}]_{1}$ alongside operating conditions may be a more convenient method to compare AOPs. This can still provide insight to $\mathrm{OH}$ radical production in AOPs by providing a relative means of $\mathrm{OH}$ comparison [39] in addition to identifying most effective conditions for $\mathrm{OH}$ radical production/utilisation for that probe. Based on the proposed $\mathrm{OH}$ pathway and previous attempts at probe based $\mathrm{OH}$ quantification, it is suggested that reporting $[\mathrm{OH}]_{1}$ or $[\mathrm{P}]$ is a more suitable method of reporting $\mathrm{OH}$ radical concentrations and assessing AOPs rather than $[\mathrm{OH}]_{T}$.

\section{Results and discussion}

\subsection{Coumarin hydroxylation during photocatalysis and cavitation}

The measured concentration profiles of coumarin and 7OHC during a two-hour PC experiment are shown in Figure 3. The initial concentration of coumarin, $\mathrm{C}_{0}$ was $100 \mu \mathrm{M}$ and $\mathrm{P} 25 \mathrm{TiO}_{2}$ catalyst loading was $0.1 \mathrm{~g} / \mathrm{L}$, irradiation began following dark adsorption equilibrium ( $6 \%$ coumarin adsorption). Coumarin was rapidly consumed within the first 20 minutes of irradiation, with a gradual slowing and near complete removal at 120 minutes. $70 H C$ was formed immediately up to a maximum concentration of $6 \mu \mathrm{M}$ at 20 minutes, after this a steady decrease until its complete removal at 120 minutes was observed. The observed trend is typical of coumarin and $7 \mathrm{OHC}$ profiles reported in PC systems $[25,27,28]$ and highlights the effective performance of $\mathrm{P} 25 \mathrm{TiO}_{2}$ as a highly oxidising photocatalyst. The performance may be attributed to its adsorption affinity towards coumarin, which facilitates reactions with surface-bound $\mathrm{OH}$ radicals.

The formation of $7 \mathrm{OHC}$ and other hydroxylated products confirms the production of $\mathrm{OH}$ radicals in the process. Monitoring $7 \mathrm{OHC}$ concentration enables indirect $\mathrm{OH}$ quantification as previously suggested [22]. However, $7 \mathrm{OHC}$ is also prone to oxidation and will compete for $\mathrm{OH}$ radicals as shown in previous studies $[38,39]$. Confirming this, it can be clearly seen in Figure 3 that the concentration of $70 \mathrm{HC}$ increases in the initial stages of the experiment followed by an eventual decrease (concentration profiles of additional products available in Figure S2 of supplementary information). When coumarin is present in excess during the initial stages of the reaction (highlighted as the inset of Figure 3), linear coumarin removal was observed attributing it to zero order kinetics. The competition for $\mathrm{OH}$ radicals by $7 \mathrm{OHC}$ and other hydroxylated products resulted in slower reaction rates of $\mathrm{OH}$ radicals with coumarin and also deviates from a zero-order reaction beyond the initial 5 minutes. At much higher initial concentrations of coumarin, zero order exhaustion of coumarin would be observed at a longer 
time period [27]. Recently, Ollis reported that the initial rate of the reaction during photocatalysis truly represents the intrinsic reaction order (zero order) whereas the whole data set might be disguised as a first order reaction [40]. The zero order PC reactions reported as first order reactions are predominantly due to the intermediates that are formed during the course of PC oxidation which interfere with the light absorption or catalyst surface saturation. In typical degradation studies using $\mathrm{PC}$, since the aim would be to mineralise the parent compound, much attention is usually not diverted towards intermediate product kinetics. Hence, the first order rate constant is reported by only tracking the parent compound's concentration. Whereas, to assess the performance of PC using a probe such as coumarin, it is required to monitor the kinetics of its intermediates/hydroxylation products. This explicitly highlights that it is the intermediates that shift the reaction order of the parent compound from zero to one. Therefore, with the $\mathrm{OH}$ radical generation being constant for the given process conditions, the $\mathrm{OH}$ radical consumption rate must also be constant and can be calculated based on the zero order constant obtained for $t=0-5 \mathrm{~min}$.

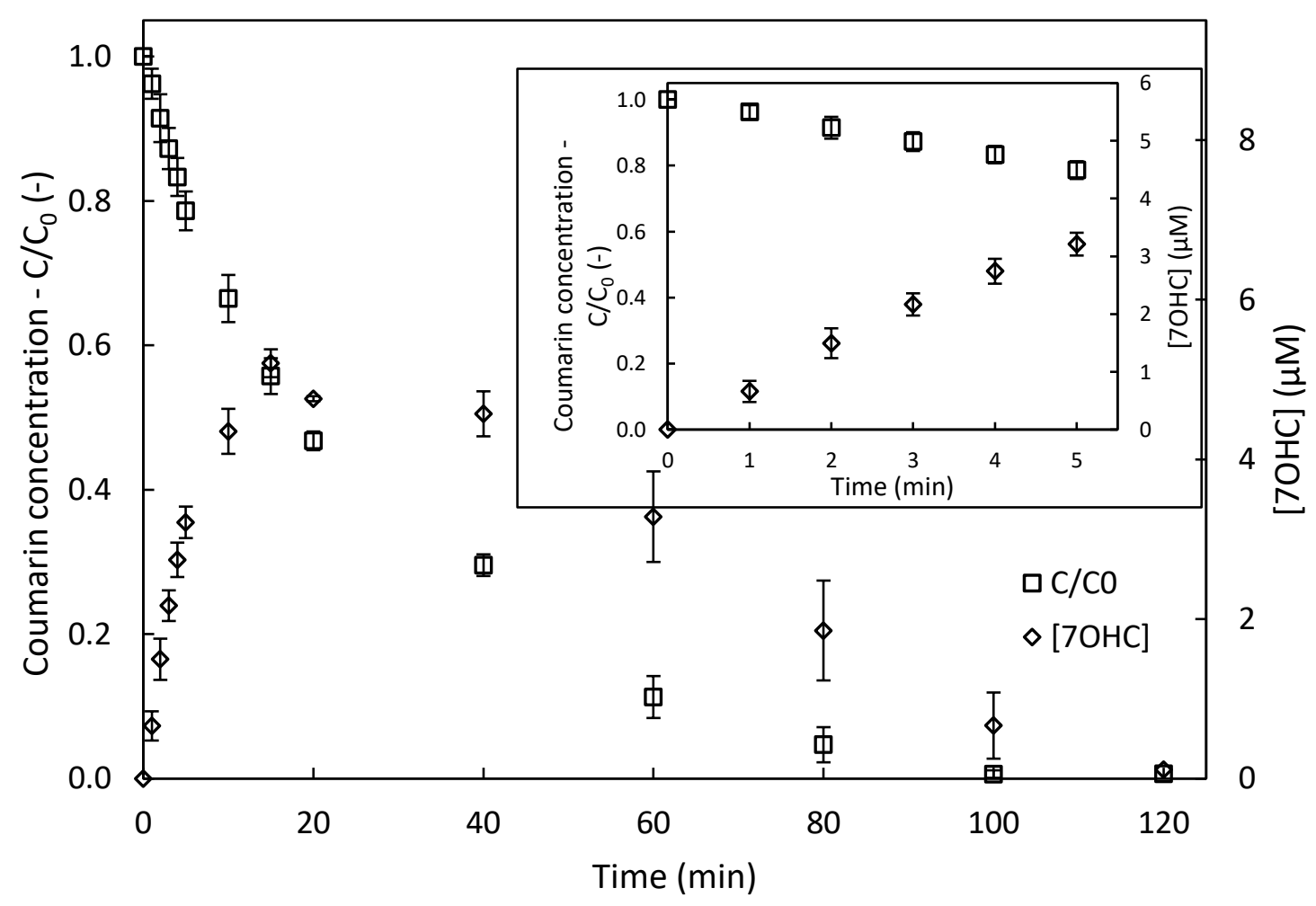

Figure 3 - Concentration profiles of coumarin $\left(C / C_{0}\right)$ and $70 H C$ during PC; $t=0-120$ minutes (Inset graph give profiles for $\mathrm{t}=0-5$ minutes), $\mathrm{C}_{0}-100 \mu \mathrm{M}, \mathrm{P} 25 \mathrm{TiO}_{2}$ loading $-0.1 \mathrm{~g} / \mathrm{L}$

Figure 4 shows the coumarin removal and $7 \mathrm{OHC}$ formation profile during cavitation treatment carried out with the same initial concentration as that of the PC experiments $\left(C_{0}-100 \mu \mathrm{M}\right)$. After 120 mins of sonication, $\sim 20 \%$ of coumarin was consumed and almost $3 \mu \mathrm{M}$ of $70 \mathrm{HC}$ had formed, indicating a much 
lower concentration and rate of $\mathrm{OH}$ formation compared to $\mathrm{PC}$ and exhibiting zero-order kinetics throughout the process (concentration profiles of additional products available in Figure S3 of supplementary information). The lower coumarin removal with $\mathrm{AC}$ may be attributed to the chemical nature of the coumarin probe and its interaction with cavities. Each region of a cavity provides a different degradation pathway [29], either pyrolysis (inside the cavity) or hydroxylation and ring opening (gas-liquid interface/bulk) and contribute to the overall probe conversion to varying degrees. It has been shown that the physico-chemical properties of a pollutant (vapour pressure, $\mathrm{pK}_{\mathrm{a}}$ and $\left.\log P_{\text {oct/wat }}\right)[29,41]$ influence which degradation pathway is most dominant due to the location of the pollutant with respect to each region. The physico-chemical properties of coumarin indicate that the main pathway of degradation during $A C$ will be hydroxylation in the bulk and interface but not pyrolytic effects. This is due to the low vapour pressure making evaporation into the cavity unlikely, and the combination of coumarin's inability to donate a proton and moderate hydrophilicity $\left(\log \mathrm{P}_{\text {oct} / \text { wat }}=1.39\right)$ restricting its location to the bulk region. Coumarin mainly in the bulk limits its contact with $\mathrm{OH}$ radicals due to their short life spans, which imply that diffusion of $\mathrm{OH}$ into the bulk to carry out oxidation reactions is mass transfer limited. Times scales of $\mathrm{OH}$ diffusion to bulk have to be smaller than its half-life to capture most of the generated radicals with minimal loss to undesirable reactions. Therefore, coumarin is less likely to come in contact with $\mathrm{OH}$ radicals in the bulk region than the gas-liquid interface and thus results in a relatively lower overall removal. 


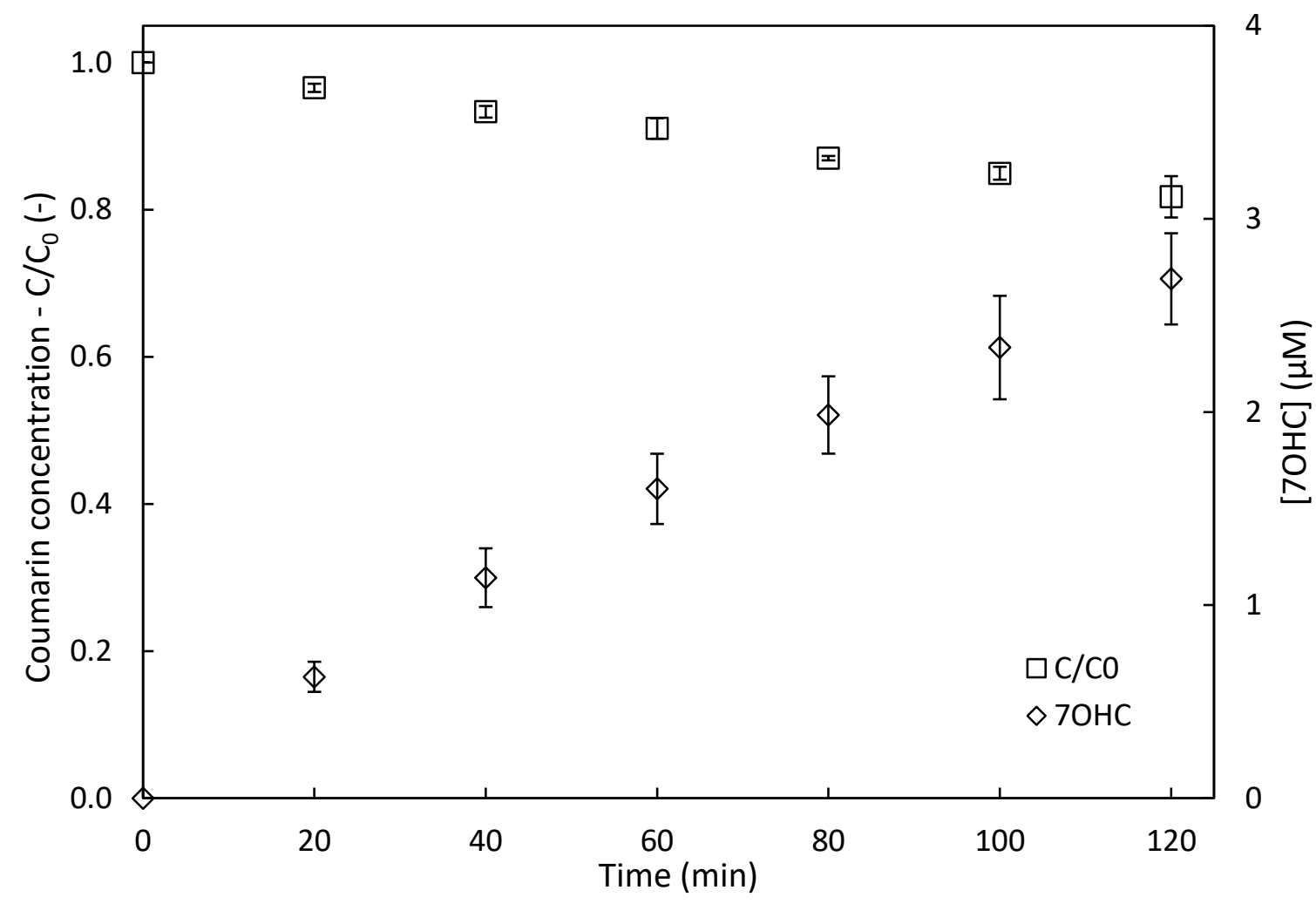

Figure 4 - Concentration profiles of coumarin $\left(C / C_{0}\right)$ and $7 \mathrm{OHC}$ during $A C$ treatment $t=0-120 \mathrm{~min}, \mathrm{C}_{0}$ $-100 \mu \mathrm{M}$

\subsection{Determination of $[\mathrm{OH}]_{1}$}

As described earlier in section 3, when using chemical probes, it is only possible to determine $[\mathrm{OH}]_{1}$ but not $[\mathrm{OH}]_{T}$ when assessing AOPs. Although it has been suggested that coumarin is more useful as a qualitative probe for $\mathrm{OH}$ radicals [42], it may be employed quantitatively to determine $[\mathrm{OH}]_{1}$ with the appropriate deliberations. It is first established that coumarin reacts to form a variety of hydroxylation products upon contact with $\mathrm{OH}$ [43]. These reactions occur by the addition of an $\mathrm{OH}$ radical to the coumarin molecule, forming a radical adduct which further reacts to generate the hydroxylated coumarin products [43]. The overall reaction occurs in 1:1 stoichiometric ratio between coumarin and $\mathrm{OH}$ radicals, so that the concentrations of these products are directly related to $[\mathrm{OH}]_{1}$ (i.e., 1 mole Coumarin +1 mole $\mathrm{OH}$ radical $\rightarrow 1$ mole mono-hydroxylated product). However, it is also possible for coumarin to undergo reactions with different stoichiometric ratios, such as di-hydroxylation. These are only considered significant during higher levels of coumarin conversion where the likelihood of mono-hydroxylated product interacting with $\mathrm{OH}$ radicals is higher. This is supported by the reaction mechanism suggested by Milenkovic et al [44] who demonstrate di-hydroxycoumarin formation from mono-hydroxycoumarins. As such, subsequent calculations with $[\mathrm{OH}]_{1}$ were only performed during low conversion regions. 
It is also possible to determine $[\mathrm{OH}]_{1}$ through the quantification of total hydroxylation products. However, during both processes, it was observed that there remained a significant difference between total hydroxylation product concentrations and [P]. During the zero-order conditions the yields of hydroxylation products from $[\mathrm{P}]$ were calculated as $21 \pm 5 \%$ and $33 \pm 7 \%$ for $\mathrm{PC}$ and $\mathrm{AC}$ respectively (relative hydroxylation product distribution available in T1 of supplementary information). The low yield of hydroxylation products in both cases may be attributed to $\mathrm{OH}$ mediated reactions favouring ring opening mechanisms [43] instead of hydroxylation, or the subsequent degradation of generated hydroxylation products.

To determine $[\mathrm{P}]$ accurately, it is also important to consider pathways where coumarin may be consumed in the absence of $\mathrm{OH}$ radicals. In PC systems, this can be via UV light photolysis, adsorption and other radical species. To account for photolysis, light control experiments were performed where the coumarin solution was irradiated without catalyst to determine the rate $\left(\sim 0.2 \mu \mathrm{M} \mathrm{min}{ }^{-1}\right)$ at which coumarin was consumed via photolysis (Figure 5). The resultant chromatograms obtained from samples did not show the formation of hydroxylated products. This indicated that the removal of coumarin is not a result of hydroxylation under photolysis, and coumarin removed via this path was accounted for in each time point according to Equation (7). This corresponded to $[\mathrm{OH}]_{1}$ for PC experiments. Coumarin may also interact with different radical species (such as superoxide radical [45]) but the degree to which these react with coumarin remains unclear. Although it is agreed hydroxycoumarins are a result of $\mathrm{OH}$-coumarin interactions, it is also possible for fragmentation products to form via $\mathrm{OH}$ radicals [43]. As it is unclear to what extent $\mathrm{OH}$-mediated fragmented products are formed compared to different radicals, Equation (7) was tentatively used to represent $[\mathrm{OH}]_{1}$ with the acknowledgement that it may be modified to account for coumarin loss due to non-OH radical attack.

For AC systems, the pyrolytic effects can be considered negligible with coumarin and degradation is likely to only occur via hydroxylation in the bulk liquid. This means any coumarin consumed during AC treatment was attributed to reaction via $\mathrm{OH}$ radicals [Equation (8)] and $[\mathrm{P}]$ was assumed the same as $[\mathrm{OH}]_{1}$. Hydrogen radicals are also generated during $A C$ processes and may offer another degradation pathway, either directly or indirectly. However, as their reactivity with coumarin is largely unknown a similar approach is taken here as with PC, where any loss via hydrogen radicals is negated. However, it is acknowledged that Equation (8) could be modified to account for this. 
$[\mathrm{OH}]_{1, P C}=[\mathrm{Cou}]_{\text {reacted }, P C}=[\mathrm{Cou}]_{\text {consumed }, P C}-[\mathrm{Cou}]_{U V}$

$[\mathrm{OH}]_{1, A C}=[\mathrm{Cou}]_{\text {reacted }, A C}=[\mathrm{Cou}]_{\text {consumed }, A C}$

where, $[\mathrm{Cou}]_{\text {reacted }}$ is the concentration of coumarin reacted, $[\mathrm{Cou}]_{\text {consumed }}$ is the total amount of coumarin removed, [Cou]uv is the concentration of coumarin removed via photolysis and subscripts PC and AC indicate the corresponding concentrations for photocatalytic and acoustic cavitation systems, respectively. Using Equations (7) and (8), the concentrations of utilised $\mathrm{OH}$ radicals were calculated for AC and PC based on measured values of [Cou $]_{\text {reacted. }}$

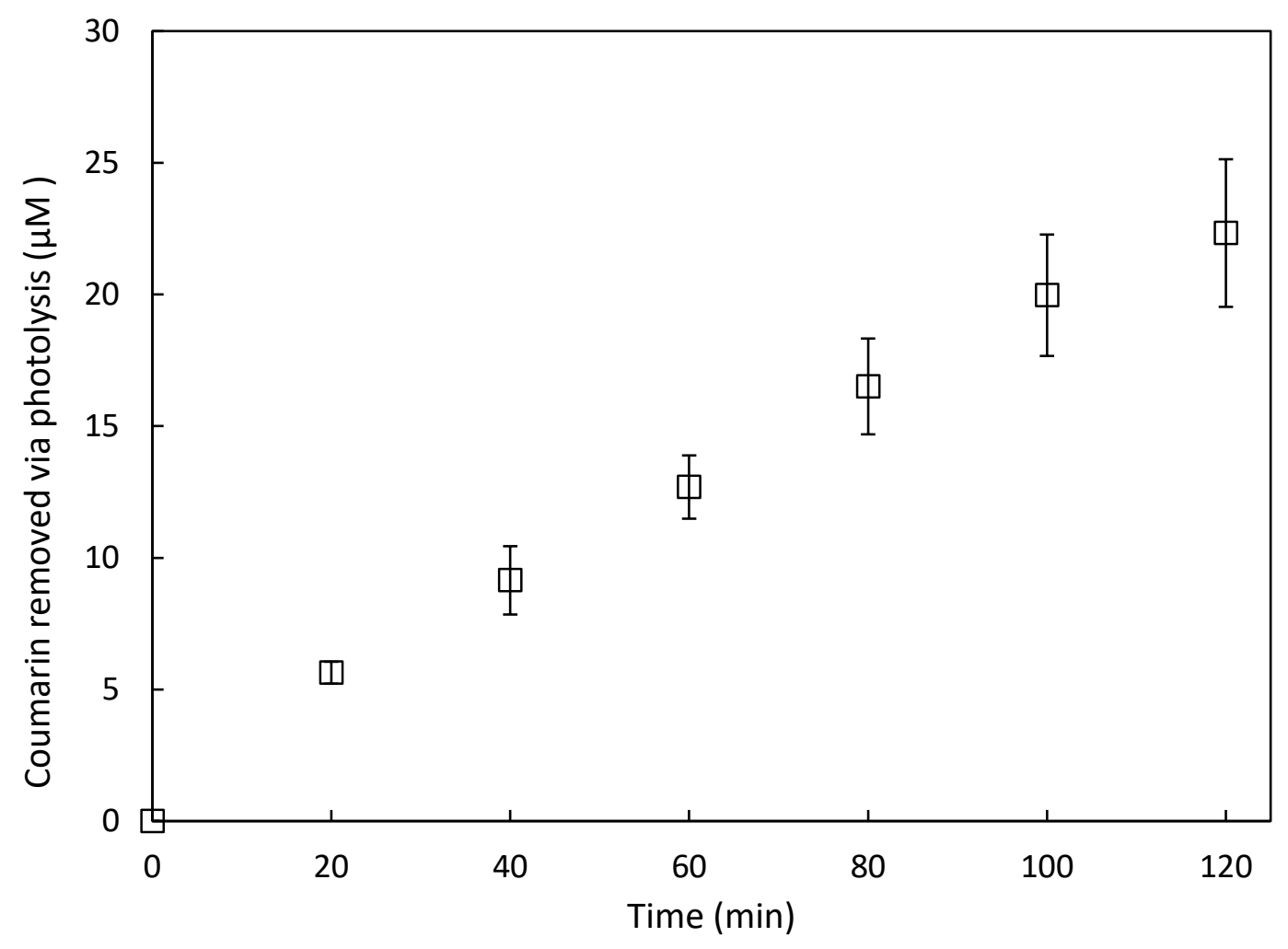

Figure 5 - Coumarin removal via photolysis (UV only), $\mathrm{t}=0-120 \mathrm{~min}, \mathrm{C}_{0}-100 \mu \mathrm{M}$

\subsection{Determination of $\beta$-yield}

Monitoring the hydroxylated products indicate that the removal of probe molecule is due to the hydroxylation reactions and not due to other undesirable reactions. As mentioned, the hydroxylated product $7 \mathrm{OHC}$ was taken as $[D]$ and used for further calculations. The corresponding $\beta$-yields for both the AOPs were then determined for zero-order conditions to reflect the expected linear production rate of $\mathrm{OH}$. Once determined for each time point, they were plotted against concentration of coumarin reacted to determine if it is constant as the reaction proceeds. Figure 6 indicates that the $\beta$-yields 
decreases as $C / C_{0}$ decreases for both processes. The trends for $\beta$ can be better understood by revisiting its expression in Equation (2), where it is defined as the ratio of $7 \mathrm{OHC}$ to coumarin reacted. The quantity of coumarin reacted is dependent on its proximity to $\mathrm{OH}$ radicals during a particular $A O P$, as expressed by $\alpha$. However, $70 \mathrm{HC}$ is also subject to $\mathrm{OH}$ radical oxidation and other possible degradation pathways. Therefore, $[7 \mathrm{OHC}]$ at a particular time is a result of its generation and consumption as expressed in Equation (9). The amount of 7OHC generated is only dependent on the amount of coumarin reacted but its consumption will vary according to the selected process and its operating conditions.

$[7 \mathrm{OHC}]=[7 \mathrm{OHC}]_{\text {generated }}-[7 \mathrm{OHC}]_{\text {consumed }}$

The gradual decrease observed with $\beta$ can be attributed to the increasing concentration of $7 \mathrm{OHC}$ in the system increasing its likelihood of reacting via one of the potential degradation pathways available. The larger error bars in the $\beta$ profile during PC may be a result of the experimental procedure selected to perform experiments. In this set-up (Figure $1 \mathrm{~b}$ and $\mathrm{c}$ ), the centre bottle may receive a greater degree of light intensity compared to those on the outside. An increased light intensity leads to an increase in PC activity [46]. When an average yield was taken of all the values for each process, it was found that $A C$ and $P C$ gave $\beta$ of $15 \pm 2 \%$ and $18 \pm 4 \%$, respectively.

The observed $\beta$ values can be explained by Equation (9). This indicates a lower $\beta$ is due to a greater amount of $7 \mathrm{OHC}$ consumption during a process. To further analyse the yields of $A C$ and PC the zeroorder degradation rate constants of coumarin and $70 \mathrm{HC}$ were determined for each process (degradation profiles available in Figure $\$ 4$ of supplementary information). $70 \mathrm{HC}$ degradation was not observed during AC treatment, therefore Individual samples of $7 \mathrm{OHC}$ at comparable concentrations $(5 \mu \mathrm{M})$ were sonicated to determine its rate constant during $\mathrm{AC}$. The zero-order rate constants were calculated for dimensionless $70 \mathrm{HC}$ profiles during $\mathrm{t}=40-120 \mathrm{~min}$ for $\mathrm{PC}$ and $\mathrm{t}=0-60 \mathrm{~min}$ for $\mathrm{AC}$ and are summarised table 1 . The larger rate constant for $7 \mathrm{OHC}$ during $\mathrm{AC}$ is likely due to the difference in physico-chemical properties which determine proximity to cavities. As both molecules have a comparable vapour pressure, their performance is likely due to differences in $\mathrm{pK}_{\mathrm{a}}$ and $\log _{\text {oct/wat }}$ values.

It was also observed that coumarin has a higher rate constant than $7 \mathrm{OHC}$ during PC. This may also be explained by considering the molecular states of the two compounds and the point of zero charge (zpc) of the $\mathrm{TiO}_{2}$ catalyst. The $z p c$ of $\mathrm{TiO}_{2}$ is known to exist between $\mathrm{pH} 6-7$ [47], at which point it will have no overall charge and its surface will be dominated by neutral species. As coumarin was entirely 
in its neutral molecular state and $70 \mathrm{HC}$ only partially $\left(\mathrm{pK}_{\mathrm{a}}\right.$ values determined using MarvinSketch software), it was more likely for coumarin to interact with surface-based $\mathrm{OH}$ radicals and hence resulted in a greater rate of removal.

\begin{tabular}{ccc}
\hline Process & $\mathrm{k}_{\mathrm{cou}}\left(\times 10^{-4}\right)$ & $\mathrm{k}_{\mathrm{7OHC}}\left(\times 10^{-4}\right)$ \\
\hline $\mathrm{AC}$ & $16 \pm 2$ & 130 \\
$\mathrm{PC}$ & $420 \pm 35$ & $120 \pm 1.5$
\end{tabular}

Table 1 - Apparent zero-order removal rate constants $\left(\mu \mathrm{M} \mathrm{min}{ }^{-1}\right)$ of coumarin and $7 \mathrm{OHC}$ (denoted $\mathrm{k}_{\mathrm{cou}}$ and $\mathrm{k}_{7 \mathrm{OHC}}$, respectively) calculated for $A C$ and PC treatment. Standard deviations are shown based on replicate experiments except for $\mathrm{k}_{7 \mathrm{OHC}}, \mathrm{AC}$ where a single experiment was performed

Figure 6 also shows $\beta$-yields calculated from previously reported studies where the same AOPs were used with coumarin aqueous solutions. Values from literature were calculated during zero-order conditions. Each data set shows a clear variation across processes, though all have a trend of gradual decrease. When considering PC processes, the lower values observed with Nagarajan et al [28] and Buck et al [27] may be explained by considering the type of lamp used to irradiate the photocatalyst and its intensity. The UV bulb used by the authors had a shorter emission wavelength than that used in this study. Shorter wavelengths have been shown to improve catalyst performance in terms of quantum yields [48] and could also cause a greater degree of $70 \mathrm{HC}$ consumption resulting in a lower $\beta$-yield. Additionally, the distance between the lamp and the reactors were not the same $(4 \mathrm{~cm}$ reported here compared to $11 \mathrm{~cm}$ for Nagarajan et al/Buck et al) which would also affect light intensity which is square of the illumination distance and accordingly, the greater distance between the lamp and the reactor in the case of Nagarajan et al and Buck et al's work would have impacted the $\mathrm{OH}$ radical production.

Similarly, from Kobayashi \& Hirano's report, a lower $\beta$ was calculated as compared to the value reported here for AC. This difference can be attributed to the types of sonication devices utilised during treatment. The data reported for $\beta$ during $A C$ was obtained using a $20 \mathrm{kHz}$ ultrasound horn, whereas the $\beta$-yield calculated for Kobayashi and Hirano [24] was found using a $500 \mathrm{kHz}$ ultrasound bath. The performance of these two methods of AC has been assessed previously [49], where the US bath shows greater performance in pollutant degradation due to a wider energy dissipation area resulting in larger amount of cavity generation. The increased degradation performance can also cause a greater removal of $7 \mathrm{OHC}$ compared to acoustic horn systems that results in a lower $\beta$ value. 
The variation in $\beta$ across processes (Figure 6 ) indicate that its application is dependent on particular operating conditions of a process and cannot be applied outside of these without being re-calculated for new conditions (for example, comparison of $\beta$ values reported by Nagarajan et al 2017 and Buck et al 2018). This indicates that, a single representative yield $(\beta)$ is not possible for a process. This is due to the complex relationship between physico-chemical properties of a probe, selected operating conditions and regions of $\mathrm{OH}$ radical availability in an $\mathrm{AOP}$, which determine the extent of $\mathrm{OH}$ utilisation. As each of these conditions (if not processes) will undoubtedly vary across studies, $[\mathrm{OH}]_{1}$ (coumarin reacted) may be a more useful means for comparing AOPs. Hence, it is reiterated that comparisons between AOPs based on $\mathrm{OH}$ radicals should be restricted to concentrations of $[\mathrm{OH}]_{1}$ alongside their chosen operating conditions.

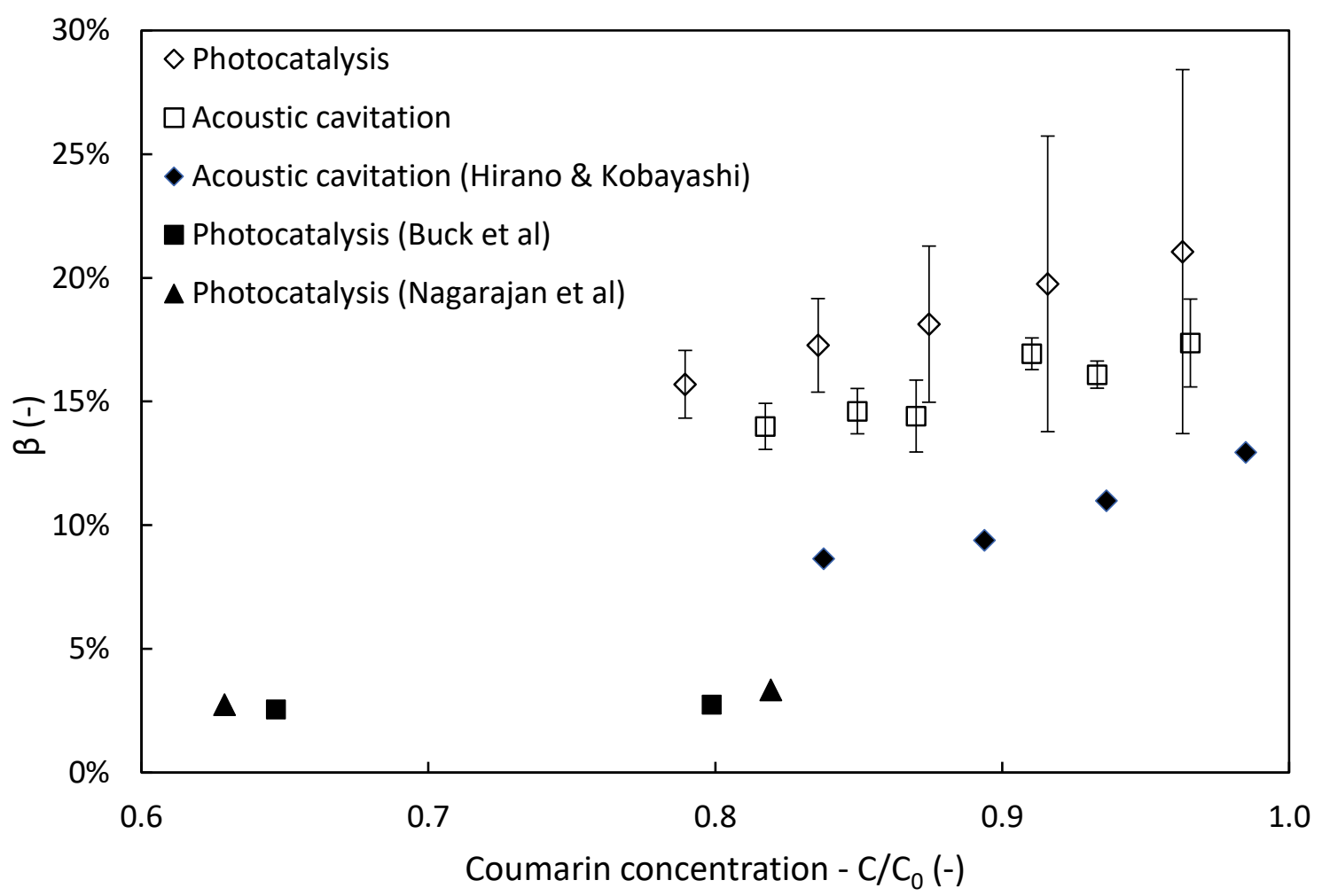

Figure $6-\beta$ vs $C / C_{0}$ for acoustic cavitation and photocatalysis processes, $C_{0}-100 \mu \mathrm{M}$, catalyst loading $-0.1 \mathrm{~g} / \mathrm{L}$, closed symbols indicate values calculated from literature, open symbols indicate values collected in the present study 


\subsection{Comparison of AOPs}

As the focus of the study is restricted to $\mathrm{OH}$ radical quantification, the following comparison is based only on the concentration of $[\mathrm{OH}]_{1}$ without accounting for process energy consumption. To compare the processes, the zero-order rate constants were calculated for the $[\mathrm{OH}]_{1}$ profiles. As seen in Figures $3 \& 4$, it is evident that $\mathrm{OH}$ radicals are utilised at a greater rate during PC than $\mathrm{AC}$. Their $\mathrm{OH}$ utilisation rates were determined to be $4 \mu \mathrm{M} \mathrm{min}{ }^{-1}$ and $0.16 \mu \mathrm{M} \mathrm{min}^{-1}$ respectively. The difference in utilisation is attributed to a greater compatibility between the physico-chemical properties of coumarin and the nature of the PC process. It is important to note that such rates are a function of the selected operating conditions. As the operating conditions are an important factor in total $\mathrm{OH}$ radical production for each process, these will also affect the rate at which $\mathrm{OH}$ radicals are utilised. Therefore, when considering any values representative of an AOP, the conditions at which they were obtained must be carefully considered.

Previous yields [25] reported for coumarin based quantification studies represent a convenient method for relating $7 \mathrm{OHC}$ to $\mathrm{OH}$ radicals, however this method requires the assumption of a constant utilised fraction $(\alpha)$ of $\mathrm{OH}$ radicals. As this was shown be unlikely for $A C$ and $P C$, employing this yield results in inaccurate reporting of total $\mathrm{OH}$ radical concentrations. It is suggested to instead report utilised $\mathrm{OH}$ radical concentrations as these are more representative of a process and its operating conditions. Employing this procedure allows for comparisons to be made across AOP and acknowledging limitations of the interactions between the probe and catalyst/bubble allows for proper interpretation of the resulting data.

\section{Conclusion}

Coumarin was employed as a probe to quantify $\mathrm{OH}$ radicals during both $\mathrm{AC}$ and $\mathrm{PC}$ processes and compare their performance. Firstly, a pathway for $\mathrm{OH}$ radical utilisation was proposed for both AOPs by defining relevant yields. Then it was determined that total $\mathrm{OH}$ radical concentrations reported in literature based on constant $\delta$-yields from $\gamma$-radiolysis (and translating it across AOPs) are misleading. Therefore, it was suggested that analytical determination of total $\mathrm{OH}$ radical production is highly unlikely and instead, $\mathrm{OH}$ radicals utilised (or the concentration of probe molecule hydroxylated) must be reported as a means for comparing AOPs. To report the $\mathrm{OH}$ radicals utilised, the concentration of coumarin reacted was calculated by negating the coumarin loss observed due to non-OH radical mediated pathways. Their zero order $\mathrm{OH}$ utilisation rate constants were determined to be $4 \mu \mathrm{M} \mathrm{min}^{-}$ 
${ }^{1}$ for $\mathrm{PC}$ and $0.16 \mu \mathrm{M} \mathrm{min}{ }^{-1}$ for $\mathrm{AC}$. The difference in rates were discussed based on the fate of $\mathrm{OH}$ radicals and the nature of the reactivity of the probe molecule. Hence it was concluded that the most effective way to use probes for $\mathrm{OH}$ quantification is to determine utilised $\mathrm{OH}$ radical concentrations, while making the appropriate considerations for undesirable degradation pathways. Employing this methodology ensures more accurate means for comparing AOPs while acknowledging the limitations of such probe-based techniques.

\section{Acknowledgement}

The authors would like to acknowledge the funding support from the Department for the Economy, Northern Ireland, United Kingdom for providing the PhD studentship to Mr. Sebastien J De-Nasri. The authors would also like to acknowledge the support from Dr. Panagiotis Manesiotis, Reader, School of Chemistry and Chemical Engineering, Queen's University Belfast, UK and his student, Mr Niall Corry for supporting with the HPLC analysis.

\section{References}

[1] A. Asghar, A.A.A. Raman, W.M.A.W. Daud, Advanced oxidation processes for in-situ production of hydrogen peroxide/hydroxyl radical for textile wastewater treatment: A review, J. Clean. Prod. 87 (2015) 826-838. https://doi.org/10.1016/j.jclepro.2014.09.010.

[2] D.B. Miklos, C. Remy, M. Jekel, K.G. Linden, J.E. Drewes, U. Hübner, Evaluation of advanced oxidation processes for water and wastewater treatment - A critical review, Water Res. 139 (2018) 118-131. https://doi.org/10.1016/j.watres.2018.03.042.

[3] D. Kanakaraju, B.D. Glass, M. Oelgemöller, Advanced oxidation process-mediated removal of pharmaceuticals from water: A review, J. Environ. Manage. 219 (2018) 189-207. https://doi.org/10.1016/j.jenvman.2018.04.103.

[4] R. Andreozzi, V. Caprio, A. Insola, R. Marotta, Advanced oxidation processes (AOP) for water purification and recovery, Catal. Today. 53 (1999) 51-59. https://doi.org/10.1016/S09205861(99)00102-9.

[5] G. Boczkaj, A. Fernandes, Wastewater treatment by means of advanced oxidation processes at basic pH conditions: A review, Chem. Eng. J. 320 (2017) 608-633. https://doi.org/10.1016/j.cej.2017.03.084. 
[6] J. Peller, O. Wiest, P. V. Kamat, Synergy of combining sonolysis and photocatalysis in the degradation and mineralization of chlorinated aromatic compounds, Environ. Sci. Technol. 37 (2003) 1926-1932. https://doi.org/10.1021/es0261630.

[7] L.A. Pérez-Estrada, M.I. Maldonado, W. Gernjak, A. Agüera, A.R. Fernández-Alba, M.M. Ballesteros, S. Malato, Decomposition of diclofenac by solar driven photocatalysis at pilot plant scale, Catal. Today. 101 (2005) 219-226. https://doi.org/10.1016/j.cattod.2005.03.013.

[8] F. Méndez-Arriaga, M.I. Maldonado, J. Gimenez, S. Esplugas, S. Malato, Abatement of ibuprofen by solar photocatalysis process: Enhancement and scale up, Catal. Today. 144 (2009) 112-116. https://doi.org/10.1016/j.cattod.2009.01.028.

[9] S.B. Doltade, G.G. Dastane, N.L. Jadhav, A.B. Pandit, D. V. Pinjari, N. Somkuwar, R. Paswan, Hydrodynamic cavitation as an imperative technology for the treatment of petroleum refinery effluent, J. Water Process Eng. 29 (2019) 100768. https://doi.org/10.1016/j.jwpe.2019.02.008.

[10] M.P. Rayaroth, U.K. Aravind, C.T. Aravindakumar, Degradation of pharmaceuticals by ultrasound-based advanced oxidation process, Environ. Chem. Lett. 14 (2016) 259-290. https://doi.org/10.1007/s10311-016-0568-0.

[11] A. Mirzaei, Z. Chen, F. Haghighat, L. Yerushalmi, Removal of pharmaceuticals from water by homo/heterogonous Fenton-type processes - A review, Chemosphere. 174 (2017) 665-688. https://doi.org/10.1016/j.chemosphere.2017.02.019.

[12] Y. Choi, D. Lee, S. Hong, S. Khan, B. Darya, J.-Y. Lee, J. Chung, S.-H. Cho, Investigation of the Synergistic Effect of Sonolysis and Photocatalysis of Titanium Dioxide for Organic Dye Degradation, Catalysts. 10 (2020) 500. https://doi.org/10.3390/catal10050500.

[13] P. Attri, Y.H. Kim, D.H. Park, J.H. Park, Y.J. Hong, H.S. Uhm, K.N. Kim, A. Fridman, E.H. Choi, Generation mechanism of hydroxyl radical species and its lifetime prediction during the plasma-initiated ultraviolet (UV) photolysis, Sci. Rep. 5 (2015) 1-8. https://doi.org/10.1038/srep09332.

[14] Q. Xiang, J. Yu, P.K. Wong, Quantitative characterization of hydroxyl radicals produced by various photocatalysts, J. Colloid Interface Sci. 357 (2011) 163-167. https://doi.org/10.1016/j.jcis.2011.01.093.

[15] R. Ono, T. Oda, Measurement of hydroxyl radicals in pulsed corona discharge, J. Electrostat. 55 (2002) 333-342. https://doi.org/10.1016/S0304-3886(01)00215-7. 
[16] P. Lukes, M. Clupek, V. Babicky, M. Arif Malik, A. Ghaffar, S. Akbar Malik, M. Šimek, M. Lupek, V. Babický, J. Gao, Y. Liu, W. Yang, B. Sun, M. Sato, J.S. Clements, V. Babic, P. Lukě, J. Schmidt, C. Ak, Generation of chemically active species by electrical discharges in water, Plasma Sources Sci. Technol. 8 (1999) 258-258. http://iopscience.iop.org/0963-0252/8/2/006.

[17] E.G. Janzen, Y. Kotake, H. Randall D., Stabilities of hydroxyl radical spin adducts of PBN-type spin traps, Free Radic. Biol. Med. 12 (1992) 169-173. https://doi.org/10.1016/08915849(92)90011-5.

[18] M.G. Steiner, C.F. Babbs, Quantitation of the hydroxyl radical by reaction with dimethyl sulfoxide, Arch. Biochem. Biophys. 278 (1990) 478-481. https://doi.org/10.1016/00039861(90)90288-A.

[19] S.A.V. Eremia, D. Chevalier-Lucia, G.L. Radu, J.L. Marty, Optimization of hydroxyl radical formation using $\mathrm{TiO} 2$ as photocatalyst by response surface methodology, Talanta. 77 (2008) 858-862. https://doi.org/10.1016/j.talanta.2008.07.056.

[20] K.I. Ishibashi, A. Fujishima, T. Watanabe, K. Hashimoto, Detection of active oxidative species in TiO2 photocatalysis using the fluorescence technique, Electrochem. Commun. 2 (2000) 207-210. https://doi.org/10.1016/S1388-2481(00)00006-0.

[21] J. Jen, M. Leu, T.C. Yang, Determination of hydroxyl radicals in an advanced oxidation process with salicylic acid trapping and liquid chromatography, 796 (1998) 283-288.

[22] A.G. Chakinala, P.R. Gogate, A.E. Burgess, D.H. Bremner, Intensification of hydroxyl radical production in sonochemical reactors, Ultrason. Sonochem. 14 (2007) 509-514. https://doi.org/10.1016/j.ultsonch.2006.09.001.

[23] M. Zupanc, M. Petkovšek, J. Zevnik, G. Kozmus, A. Šmid, M. Dular, Anomalies detected during hydrodynamic cavitation when using salicylic acid dosimetry to measure radical production, Chem. Eng. J. (2020) 125389. https://doi.org/10.1016/j.cej.2020.125389.

[24] K. Hirano, T. Kobayashi, Coumarin fluorometry to quantitatively detectable $\mathrm{OH}$ radicals in ultrasound aqueous medium, Ultrason. Sonochem. 30 (2016) 18-27. https://doi.org/10.1016/j.ultsonch.2015.11.020.

[25] J. Zhang, Y. Nosaka, Quantitative detection of $\mathrm{OH}$ radicals for investigating the reaction mechanism of various visible-light TiO2photocatalysts in aqueous suspension, J. Phys. Chem. C. 117 (2013) 1383-1391. https://doi.org/10.1021/jp3105166.

[26] A. Fujishima, T. Watanabe, K. Hashimoto, K. Ishibashi, Quantum yields of active oxidative 
species formed on TiO2 photocatalyst, J. Photochem. Photobiol. A Chem. 134 (2000) 139142.

[27] C. Buck, N. Skillen, J. Robertson, P.K.J. Robertson, Photocatalytic $\mathrm{OH}$ radical formation and quantification over TiO2P25: Producing a robust and optimised screening method, Chinese Chem. Lett. 29 (2018) 773-777. https://doi.org/10.1016/j.cclet.2018.04.022.

[28] S. Nagarajan, N.C. Skillen, F. Fina, G. Zhang, C. Randorn, L.A. Lawton, J.T.S. Irvine, P.K.J. Robertson, Comparative assessment of visible light and UV active photocatalysts by hydroxyl radical quantification, J. Photochem. Photobiol. A Chem. 334 (2017) 13-19. https://doi.org/10.1016/j.jphotochem.2016.10.034.

[29] T. Sivasankar, V.S. Moholkar, Physical insights into the sonochemical degradation of recalcitrant organic pollutants with cavitation bubble dynamics, Ultrason. Sonochem. 16 (2009) 769-781. https://doi.org/10.1016/j.ultsonch.2009.02.009.

[30] W. Choi, S. Kim, S. Cho, H.-I. Yoo, M.-H. Kim, Photocatalytic reactivity and diffusing $\mathrm{OH}$ radicals in the reaction medium containing TiO2 particles, Korean J. Chem. Eng. 18 (2001) 898-902. https://doi.org/10.1007/BF02705615.

[31] V. Leandri, J.M. Gardner, M. Jonsson, Coumarin as a Quantitative Probe for Hydroxyl Radical Formation in Heterogeneous Photocatalysis, J. Phys. Chem. C. (2019) acs.jpcc.9b00337. https://doi.org/10.1021/acs.jpcc.9b00337.

[32] I. Draganic, The Radiation Chemistry of Water, Elsevier Science, 2012. https://books.google.co.uk/books?id=DF-1K6weadgC.

[33] I.G. Draganić, M.T. Nenadović, Z.D. Draganić, Radiolysis of $\mathrm{HCOOH}+\mathrm{O} 2$ at pH 1.3-13 and the yields of primary products in $y$ radiolysis of water, J. Phys. Chem. 73 (1969) 2564-2571. https://doi.org/10.1021/j100842a018.

[34] E.J. Hart, $y$-Ray-Induced Oxidation of Aqueous Formic Acid-Oxygen Solutions. Effect of pH, J. Am. Chem. Soc. 76 (1954) 4198-4201. https://doi.org/10.1021/ja01645a056.

[35] B.H.J. Bielski, A.O. Allen, The radiolotic yield of reducing radicals in neutral aqueous solution, Int. J. Radiat. Phys. Chem. 1 (1969) 153-163. https://doi.org/10.1016/0020-7055(69)90045-X.

[36] J.H. Baxendale, A.A. Khan, The pulse radiolysis of p-nitrosodimethylaniline in aqueous solution, Int. J. Radiat. Phys. Chem. 1 (1969) 11-24. https://doi.org/10.1016/00207055(69)90018-7. 
[37] V. Leandri, J.M. Gardner, M. Jonsson, Coumarin as a Quantitative Probe for Hydroxyl Radical Formation in Heterogeneous Photocatalysis, J. Phys. Chem. C. 123 (2019) 6667-6674. https://doi.org/10.1021/acs.jpcc.9b00337.

[38] H. Czili, A. Horváth, Applicability of coumarin for detecting and measuring hydroxyl radicals generated by photoexcitation of TiO2 nanoparticles, Appl. Catal. B Environ. 81 (2008) 295302. https://doi.org/10.1016/j.apcatb.2008.01.001.

[39] G. Žerjav, A. Albreht, I. Vovk, A. Pintar, Revision of terephthalic acid and coumarin as probes for photoluminescent determination of hydroxyl radical formation rate in heterogeneous photocatalysis, Appl. Catal. A Gen. (2020) 117566. https://doi.org/10.1016/j.apcata.2020.117566.

[40] D.F. Ollis, Kinetics of Photocatalyzed Reactions: Five Lessons Learned, Front. Chem. 6 (2018) 1-7. https://doi.org/10.3389/fchem.2018.00378.

[41] V.K. Saharan, A.B. Pandit, P.S. Satish Kumar, S. Anandan, Hydrodynamic cavitation as an advanced oxidation technique for the degradation of Acid Red 88 dye, Ind. Eng. Chem. Res. 51 (2012) 1981-1989. https://doi.org/10.1021/ie200249k.

[42] A.C. Maier, E.H. Iglebaek, M. Jonsson, Confirming the Formation of Hydroxyl Radicals in the Catalytic Decomposition of $\mathrm{H} 2 \mathrm{O} 2$ on Metal Oxides Using Coumarin as a Probe, ChemCatChem. 11 (2019) 5435-5438. https://doi.org/10.1002/cctc.201901316.

[43] G. Louit, S. Foley, J. Cabillic, H. Coffigny, F. Taran, A. Valleix, J.P. Renault, S. Pin, The reaction of coumarin with the $\mathrm{OH}$ radical revisited: Hydroxylation product analysis determined by fluorescence and chromatography, Radiat. Phys. Chem. 72 (2005) 119-124. https://doi.org/10.1016/j.radphyschem.2004.09.007.

[44] D.A. Milenković, D.S. Dimić, E.H. Avdović, A.D. Amić, J.M. Dimitrić Marković, Z.S. Marković, Advanced oxidation process of coumarins by hydroxyl radical: Towards the new mechanism leading to less toxic products, Chem. Eng. J. 395 (2020) 124971. https://doi.org/10.1016/j.cej.2020.124971.

[45] A. Wafi, E. Szabó-Bárdos, O. Horváth, É. Kristóf-Makó, M. Jakab, B. Zsirka, Coumarin-based quantification of hydroxyl radicals and other reactive species generated on excited nitrogendoped TiO2, J. Photochem. Photobiol. A Chem. (2020) 112913. https://doi.org/10.1016/j.jphotochem.2020.112913.

[46] A. V. Emeline, V. Ryabchuk, N. Serpone, Factors affecting the efficiency of a photocatalyzed 
process in aqueous metal-oxide dispersions, J. Photochem. Photobiol. A Chem. 133 (2002) 89-97. https://doi.org/10.1016/s1010-6030(00)00225-2.

[47] K.E. O'Shea, E. Pernas, J. Saiers, Influence of mineralization products on the coagulation of TiO2 photocatalyst, Langmuir. 15 (1999) 2071-2076. https://doi.org/10.1021/la9806808.

[48] U. Stafford, K.A. Gray, P. V. Kamat, Photocatalytic degradation of 4-chlorophenol: The effects of varying TiO2 concentration and light wavelength, J. Catal. 167 (1997) 25-32. https://doi.org/10.1006/jcat.1997.1511.

[49] P.R. Gogate, I.Z. Shirgaonkar, M. Sivakumar, P. Senthilkumar, N.P. Vichare, A.B. Pandit, Cavitation reactors: Efficiency assessment using a model reaction, AIChE J. 47 (2001). https://doi.org/10.1002/aic.690471115. 